\title{
ANAESTHETIC DEATHS IN ALBERTA
}

\author{
E. A. GaIN, B.A., M D.*
}

IN 1952 the Alberta Divisıon of the Canadian Anaesthetist's Society decided that it would like to know the situation concerning anaesthesia in this province. As there were only approximately twenty certified trained anaesthetists at that time, a large proportion of anaesthetics must be administered by untrained individuals, mostly general practitioners Therefore it was the feeling of the Alberta Division that hospital training in anaesthesia for the future general practitioner should be as compulsory as is traming in medicine, surgery and obstetrics, before he is licensed to practise. Incorrect anaesthesia can be the most lethal of medical procedures. Therefore steps were taken to have established a committee to investigate deaths following anaesthesia and surgery.

In September, 1952, at the annual meeting of the Alberta Division of the Canadian Medical Association a committee was formed to study this matter and to report the results of 1 ts wolk. The committee commenced this study in January, 1953, reviewing the charts of all patients who died within thirty days of anaesthesia and surgery. In Alberta all such charts must by law be submitted to the Department of Public Health. The officers of this department kindly sent all of these charts to this committee.

The committee's purpose was to determine how well or how poorly anaesthesia and surgery were being performed in this province. No attempt was made to carry out an academ c study of the many factors involved A total of 168 charts were received. Attempts were made to obtain all possible information but rarely could any more information be obtained than was already in the case record. Anaesthetic records were almost always inadequate. The greatest single deficiency was in autopsy examinations which were performed in only 51.19 per cent of cases. As a result of this lack of information there were undoubtedly many more anaesthetic deaths and the figures which follow are conservative.

Of the 168 deaths there were 26 which were classified as preventable anaesthetic deaths, 46 as preventable surgical deaths, and 96 which were classified as inevitable fortuitous or unassessable. The latter classification was necessary because sufficient information could not be obtamed to classify them in any other way.

The distribution according to the type of surgery is shown in Table I.

It will be noted that there were no anaesthetic deaths associated with thoracic and neurosurgical procedures. This may be owing, in part at least, to the fact that these procedures are usually done in larger centres by trained and wellequipped anaesthetists. The anaesthetic deaths are high in the ear, nose, and throat and other head and neck procedures. The cause was invariably some respiratory difficulty and none of these patients had an endotracheal anaesthesia.

"Edmonton, Alberta. 
TABLE I

\begin{tabular}{|c|c|c|c|c|}
\hline Operation & $\begin{array}{c}\text { Anaesthetic } \\
\text { death }\end{array}$ & $\begin{array}{c}\text { Surgıcal } \\
\text { death }\end{array}$ & $\begin{array}{c}\text { Inevitable } \\
\text { forturtous deaths } \\
\text { unassessable }\end{array}$ & Total \\
\hline Ear-nose-throat & 3 & 3 & 3 & 9 \\
\hline Other-head \& neck & 3 & 1 & 1 & 5 \\
\hline Thoracic & 0 & 4 & 6 & 10 \\
\hline Gastric & 3 & 6 & 5 & 14 \\
\hline Biliary & 2 & 8 & 10 & 20 \\
\hline Small and large bowel & 5 & 11 & 17 & 33 \\
\hline Hernia & 4 & 1 & 3 & 8 \\
\hline Endoscopy & 0 & 1 & 1 & 2 \\
\hline Orthópaedic & 1 & 2 & 7 & 10 \\
\hline Obstetrical & 1 & 0 & 4 & $\mathbf{5}$ \\
\hline Gynaecological & 2 & 2 & 2 & 6 \\
\hline Neurosurgical & 0 & 0 & 26 & 26 \\
\hline \multirow[t]{3}{*}{ Others } & 2 & 7 & 11 & 20 \\
\hline & - & - & - & - \\
\hline & 26 & 46 & 96 & 168 \\
\hline
\end{tabular}

Tables II and III help to disprove the widely held belief amongst practitioners that open ether is safe even in the hands of the inexperienced. Cyclopropane contributed the lowest incidence of deaths even though it is more often used in the poor-risk patient. This result is likely due to the fact that it is usually used by the trained and not the untramed anaesthetsist.

TABLE II

Number of Each Anaesthetic Administered

\begin{tabular}{cccccccc}
\hline Ether & Cyclopropane & Pentothal & Spinal & $\begin{array}{l}\text { Spinal \& } \\
\text { Pentothal }\end{array}$ & Local & None & Total \\
\hline 42 & 25 & 27 & 20 & 28 & 17 & 14 & 168 \\
\hline
\end{tabular}

TABLE III

Anaesthetic Agents Associated with Anaesthetic Deaths

\begin{tabular}{ccccccc}
\hline Ether & Cyclopropane & Pentothal & Spinal & $\begin{array}{c}\text { Spinal \& } \\
\text { Pentothal }\end{array}$ & Local & Total \\
\hline 9 & 2 & 7 & 3 & 4 & 1 & 26 \\
\hline
\end{tabular}

Pentothal and spinal produced the results expected. Several of the cardiac arrests occurred with the combination of spinal plus pentothal. The one death with local was the result of procaine with epinephrine used in conjunction with self-administered trichloroethylene. This combination can be as dangerous as cyclopropane and epinephrine but unfortunately this fact is not generally known.

It will be noted that there is no mention of muscle relaxants. Relaxants were only used in 4 of the 26 cases, and in none of these 4 could the relaxant in the dose used and time administered have been responsible for the death. 
TABLE IV

Cause of Death in 26 Cases classified as Anaesthetic Deaths

1. Anaesthetic overdose with respiratory and/or circulatory fallure 10

2 Respiratory obstruction during anaesthesia $\quad 2$

3. Respiratory obstruction following anaesthesia $\quad 3$

4. Regurgitation or vomiting with aspiration 1

5 Convulsions during ether anaesthesia 1

6 Acute cardrac arrest, probably due to

(a) Movement of the patient 2

(b) Reflex disturbances with possible hypoxia and/or hypercarbia 3

(c) Ventricular fibrillation due to drug incompatibulity 1

(d) Inadequate ventilation 3

As expected and shown in Table IV the cause of death was most often associated with some respiratory derangement. Acute cardiac arrest is included as most cases were believed to be the result of the anaesthetic. The cause of this complication is of course often difficult to discover but is usually an improperly administered anaesthetrc. Of these 9 cardiac arrests only 2 of the patients were in the older age group, none involved intrathoracic surgery, and only one was a poor risk. Therefore the committee felt justıfied in assigning their deaths to the anaesthetic.

Out of the 168 cases, 75 involved certfied anaesthetists, 79 non-certified or general practitioner anaesthetısts. In the remaining 14 cases the patient did not have an anaesthetic.

Ot the 26 anaesthetic deaths, 8 involved certified anaesthetists and 18 noncertufied anaesthetists. Unfortunately it proved impossible to obtain figures giving the total numbers of anaesthetics administered and operations performed in this province in 1953. Nor could figures for the number of anaesthetics administered by certified and non-certified anaesthetısts be obtained.

As mentioned previously the purpose of this committee is to discover the true state of anaesthesia and surgery in Alberta, to decide what are the deficiencies, and what steps should be taken to correct them. The members of the Alberta Division of the Canadian Anaesthetists' Society have in the past few years attempted through the pages of the Alberta Medical Bulletin to give information concerning safety in anaesthesia to the general practitioners in this province. In addition, the author, at the request of the President of the Alberta Division of the Canadian Medical Association, is, conducting a speaking tour of the district medical societies, attempting to point out and correct the errors which have been responsible for the anaesthetic deaths in this province.

The aim of this communication has been to show what the Alberta nembers are doing to improve anaesthesia in their province, and to solicit the support of the Canadian Anaesthetists' Society for their belief that clinical training in anaesthesia is as necessary as is clinical training in medicine, surgery and obstetrics, before the recent graduate is permitted to set forth into general practice, where in many areas he must because of necessity, often administer anaesthetics. 